\title{
MIASIS INTESTINAL
}

\author{
Dr. LEONIDAS POBLETE
}

Cátedra de Pediatria Prof. A. Scroggie.

Hospital de Niños "Roberto del Río".

Hemos creído de interés relatar un caso de Mliasis intestinal, ya que los enfermos descritos de esta afeccion en nuestra literatura son escasos. Además, en algunos casos de diarreas en niños, bajo ciertas condiciones, habría que considerar la miasıs en el diagnóstico diferencial.

Se denomina miasis o myiasis a diversas lesiones patológicas producidas en el hombre por larvas de moscas y se pueden clasificar según la parte del organismo que es atacada, en:

1. Miasis cutáneas. Estas pueden ser primarias o secundarias.

2. Miasis cavitarias: nasales, auditivas y oculares. En este tipo de miasis los insectos ponen sus huevos en las regiones parasitadas atraídos por olores particulares en individuos con enfermedades crónicas o bien en individuos sanos.

En nuestro país han sido descritos numerosos casos por varios autores, predominando las formas nasales, oculares $\mathrm{y}$ auditivas en el mismo orden anotado.

3. Miasis del aparato digestivo. Estas pueden ser: orales, faríngeas, esofágicas $\mathrm{y}$ por último gastro-intestinales.

Las primeras pueden ser concomitantes y se explica que así sea, por la relación de vecindad de las cavidades. Esto da margen a que con cierta facilidad las larvas caminen de una región a otra. Son generalmente primitivas las de las fosas nasales o de la boca.

Del tipo gastro-intestinal, Donoso Barros en su tesis de 1947 cita en Chile hasta ese momento 4 casos. En la revisión hecha por nosotros no encontramos otras referencias bibliográficas. Este hecho es el que nos ha movido a publicar nuestro caso observado hace ya algún tiempo (año 1948).

La presencia de larvas en el tubo digestivo parece un tanto anacrónica, pues sería factible pensar que las condiciones del aparato digestivo impedirian el desarrollo y supervivencia de ellas. Experiencias de Laboratorio verificadas tratando de reproducir las condiciones "in vivo" han demostrado que las larvas sobreviven 3 o más horas, tiempo suficiente para que en un proceso digestivo alterado puedan dichas larvas franquear la barrera pilórica y continuar su trayecto a través del tubo digestivo.

La miasis de nuestro caso clínico corresponde a este grupo menos numeroso $y$ discutido.

\section{CASO CLÍNICO}

M. N. A. 1 año 4 meses. Peso 8.600 gr. Consulta en el Policlínico del Hospital Barros Luco. Su enfermedad habría comenzado hace 45 días. La madre relata que las deposiciones eran liquidas con mucosidades. Ha estado sometido a tratamientos indicados por médico y con remedios caseros. El día que lo traen a consulta, la madre ha observado que el niño expulsa en sus deposiciones elementos vivos ovalados y que presentan movimientos en su eje longitudinal.

Antecedentes hereditarios: Padres sanos. Serología negativa hace 1 año. 3 hermanos vivos y sanos, uno fallecido ignora la causa. No acusa contagios ni enfermedades intra familiares.

Antecedentes personales: Nacido de parto normal, de término, con un peso de $3 \mathrm{~kg}$. No ha sido vacunado.

Enfermedades anteriores: Ha sufrido frecuentes trastornos nutritivos agudos.

Alimentación: Seno exclusivo en forma irregular en los primeros días; después cada 4 horas 5 veces hasta los 8 meses, fecha en que agrega sopas y mamaderas de harina tostada en agua (ulpo); a veces leche en polvo o condensada. Este 
tipo de alimentación, con leves variaciones, se mantiene hasta la fecha. No ha comido huevos ni carne. Jugos de fruta a yeces.

Examen físico: Niño en pésimas condiciones nutritivas. Paniculo $\mathrm{y}$ turgor muy disminuídos.

Hosición activa: Llora constantemente. Estátıea y dinámica atrasada. En el momento del examen, el niño presenta angustia, borborigmos intestinales y al parecer, violentas contracciones dando origen, al final, a la expulsión de heces muy liquidas, con escaso mucus en los cuales, en forma explosiva, salen, como proyectiles, elementos vivos. De inmediato se toma muestra de ellos y son enviados a un entomólogo (Sr. Herrera) el que informa posteriormente que se trata de larvas de la mosca Calliphora Vomitoria. Después de la expulsión de las deposiciones el niño queda tranquilo y en estado de agotamiento. El resto del examen físico no revela otras alteraciones que el de su profunda distrofia.

Evolución: Desgraciadamente se ignora la evolución posterior.

Habitación y hábitos higiénicos: Esta familia vive en una mejora a la orilla del canal San Joaquín. Choza de fonolita y madera, sin agua potable ni luz eléctrica ni servicios hìgiénicos. El padre trabaja como obrero libre en el Matadero Municipal.

Diagnóstico: Distrofia grave, Miasis intestinal.

Tratamiento: Régimen dietético especial. Alejamiento del enfermo del medio infectado de moscas. Sulfathiazol $0.20 \mathrm{gr}$. por kg. para seguir con $0.10 \mathrm{gr}$. por $\mathrm{kg}$. durante 16 dias.

Discusión: Al hacer el análisis de la literatura pertinente a las Miasis intestinales, se encuentran descritos numerosos casos en diversas partes. Rhodes describe en Tanganyka 7 miasis intestinales en ninos entre 7 y 20 meses producidas por las moscas Megasilia de la Familia de las Phoridiae. Este insecto pone sus huevos en las frutas $u$ otros alimentos, especialmente en los mangos. Micks, relata un caso de miasis producido por la Leptocera Venalicia. Entre nosotros, Donoso Barros describe otro caso con diarrea por larvas de $r$ sychoda y Silva Lampos ouro provocado por 'I ubifera Tenax.

Algunos autores europeos describen miasis intestinales por Piophila Casei acorde con la costumbre de consumir quesos con larvas. Otros aún describen como agentes productores a la Hermetia Illusens, la Calliphora Vomitoria y la mosca común.

Como se observa son numerosos los tipos de moscas que en condiciones especiales son capaces de producir dicha enfermedad.

Al considerar la miasis, hay que tomar en cuenta que esta puede ser una pseudo miasis, debido a que las heces dejadas en recipientes sucios o en pañales expuestos en ambiente cargado de estos insectos, ellos pueden colocar sus huevos en las deposiciones, donde, en condiciones favorables, alcanzan en dos o tres horas a salir las larvas.

La Calliphora Vomitoria en este caso, es la llamada comúnmente "mosca azul". Es un insecto más o menos de 7 a $13 \mathrm{~mm}$. pone sus huevos en la carne fresca o en descomposición. Cada hembra pone alrededor de 200 huevos de los que nacen según el clima y la época al cabo de 24 horas, larvas muy voraces y que crecen con rapidez. Al cabo de doce días pasan al estado de pupas para ser insecto perfecto en igual tiempo. Este insecto, fuera de dar en circunstancias especiales estas miasis, es vector de bacilos tipo coli, disentéricos, estafilococos, vibrion colérico, etc.

En los casos forturitos de diarreas por larvas de moscas, la sintomatología es pobre, porque la diarrea es fugaz. En los casos crónicos en cambio, puede haber un violento cuadro diarreico (consecuencia de la irritación de la mucosa intestinal), que lleva al enfermo a la desnutrición y como complicación a trastornos nerviosos graves.

Como tratamiento actual se emplea un evacuante intestinal del tipo del aceite de ricino $y$ antibióticos que ataquen la flora que ,en condiciones especiales producidas por la infestación de larvas, agrava el cuadro diarreico.

La forma como el hombre es infestado es variada: pueden llegar las larvas en alimentos ingeridos crudos; por beber aguas insalubres infectadas por acequias con inmundicias; por la proximidad de letrinas mal protegidas o por la ovipostura directa del insecto. Hay necesidad de con- 